\title{
Correction to: Probability of Alzheimer's disease based on common and rare genetic variants
}

\author{
Valentina Escott-Price ${ }^{1 *}$ and Karl Michael Schmidt ${ }^{2}$
}

\section{Correction to: Alz Res Therapy 13, 140 (2021)}

https://doi.org/10.1186/s13195-021-00884-7

Following the publication of the original article [1] the authors noticed that the published Fig. 3 is incorrect. The original article [1] has been updated.

Below is the correct Fig. 3.

\section{Author details}

'Dementia Research Institute, Division of Psychological Medicine and Clinical Neurosciences, School of Medicine, Cardiff University, Hadyn Ellis Building, Maindy Rd, Cardiff CF24 4HQ, UK. ${ }^{2}$ School of Mathematics, Cardiff University, Senghennydd Road, Cardiff CF24 4AG, UK.

Published online: 20 September 2021

\section{Reference}

1. Escott-Price V, Schmidt KM. Probability of Alzheimer's disease based on common and rare genetic variants. Alz Res Therapy. 2021;13(1):140. https:// doi.org/10.1186/s13195-021-00884-7.

* Correspondence: escottpricev@cardiff.ac.uk

'Dementia Research Institute, Division of Psychological Medicine and Clinical Neurosciences, School of Medicine, Cardiff University, Hadyn Ellis Building, Maindy Rd, Cardiff CF24 4HQ, UK

Full list of author information is available at the end of the article

(c) The Author(s). 2021 Open Access This article is licensed under a Creative Commons Attribution 4.0 International License, which permits use, sharing, adaptation, distribution and reproduction in any medium or format, as long as you give appropriate credit to the original author(s) and the source, provide a link to the Creative Commons licence, and indicate if changes were made. The images or other third party material in this article are included in the article's Creative Commons licence, unless indicated otherwise in a credit line to the material. If material is not included in the article's Creative Commons licence and your intended use is not permitted by statutory regulation or exceeds the permitted use, you will need to obtain permission directly from the copyright holder. To view a copy of this licence, visit http://creativecommons.org/licenses/by/4.0/. The Creative Commons Public Domain Dedication waiver (http://creativecommons.org/publicdomain/zero/1.0/) applies to the data made available in this article, unless otherwise stated in a credit line to the data. 


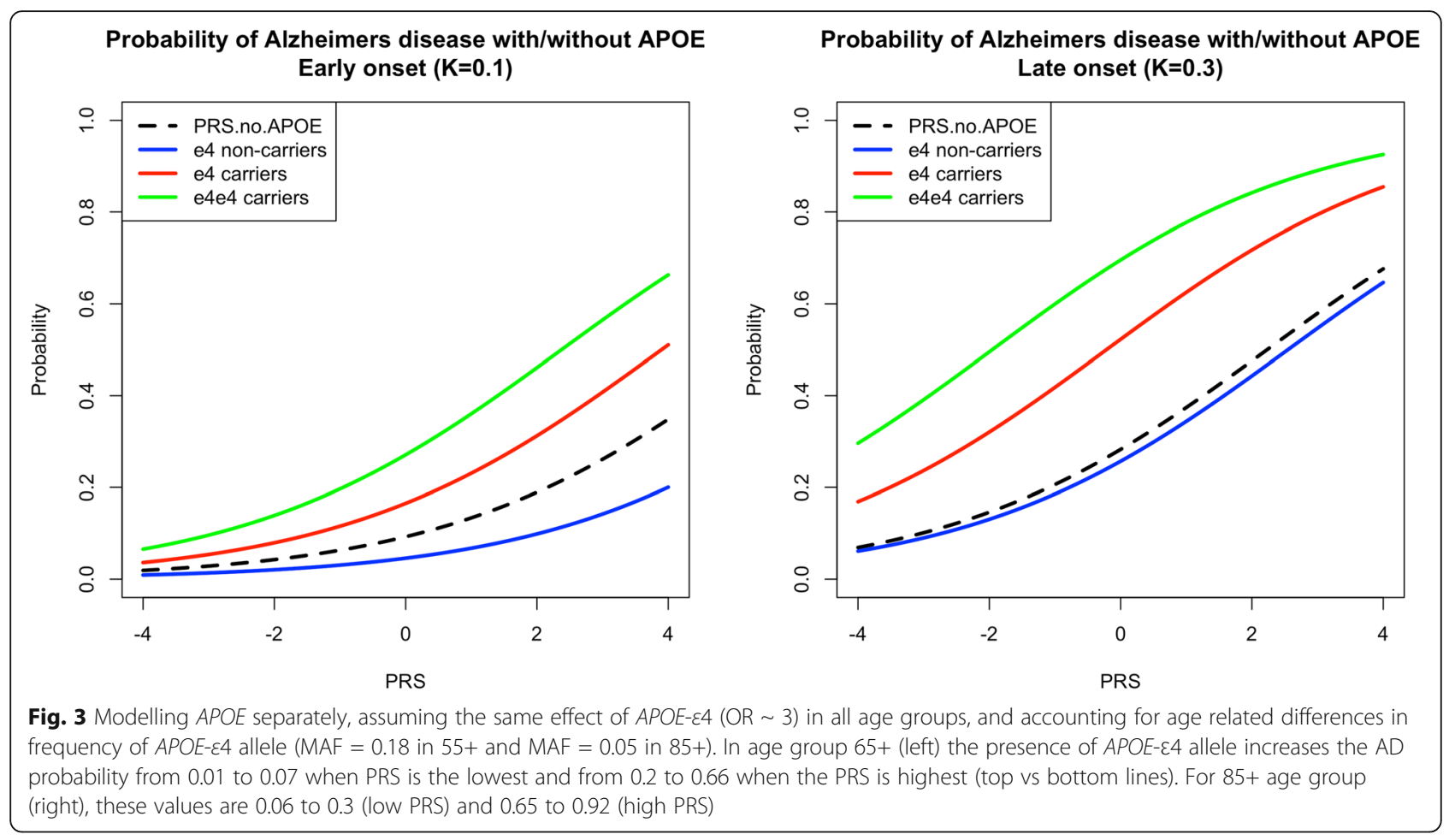

